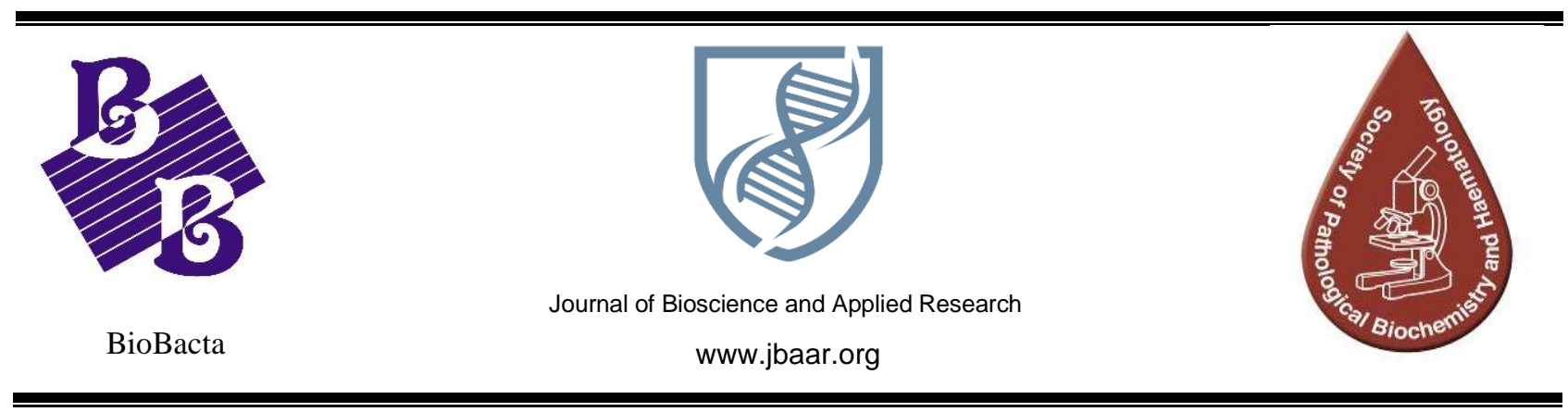

\title{
Ameliorating role of Foeniculum vulgare (fennel) and Pimpinella anisum (anise) against Zinc oxide nanoparticles induced hepatotoxicity in male albino rats
}

\author{
Amel I. Barakat \\ Zoology Department, Faculty of Science, Damanhour University, Egypt \\ Corresponding author: dr_amlbarakat@yahoo.com
}

DOI: 10.21608/jbaar.2019.146878

\begin{abstract}
Medicinal plants have been used traditionally worldwide for the prevention and treatment of liver disease. Pimpinella anisum (Anise) or Foeniculum vulgare (Fennel) are used frequently as spices. The present study aimed to investigate the potential protective effect of Anise and Fennel aqueous extract, against $\mathrm{ZnO}$ nanoparticles which induced hepatotoxicity in rats. Administration of $\mathrm{ZnO}$ nanoparticles $(30 \mathrm{mg} / \mathrm{kg} / \mathrm{kg}$. b.wt) oral daily for 4 weeks resulted in liver damage manifested by a significant increase in serum AST, ALT, and ALP. Increase in MDA and decrease in CAT in the group treated by $\mathrm{ZnO}$ nanoparticles. Immunohistochemistry is observed by the level of Interleukin-6. Rats treated orally with aqueous seed extracts of Pimpinella anisum (Anise, $125 \mathrm{mg} / \mathrm{kg}$ ) and Foeniculum vulgare (Fennel, $150 \mathrm{mg} / \mathrm{kg}$ ) for 4 weeks and intoxicated with $\mathrm{ZnO}$ nanoparticles showed significant protection against an induced increase in serum liver enzyme (AST, ALT, ALP), restored and ameliorate the increased interleukin-6 level. A significant corrective effect of either Anise or fennel aqueous extract on biochemical parameters were supported by histopathological examination of the rats.

In conclusion, these data indicated that the aqueous seed extracts of Foeniculum vulgare (Fennel) and Pimpinella anisum (Anise) possessed a hepatoprotective activity against hepatotoxicity induced by $\mathrm{ZnO}$ nanoparticles in rats.
\end{abstract}

Keywords: Foeniculum vulgare (Fennel) and Pimpinella anisum (Anise), ZnO nanoparticles. 


\section{1- Introduction}

Nanotechnology, a combination of principles involving biology, physical and chemical that creates nano-sized particles holding particular functions. For this purpose, noble metal nanoparticles like silver, gold, platinum, palladium. And non-metallic, inorganic oxides like zinc oxide, titanium oxide have been widely exploited because of their unique electronic, mechanical, optical, chemical, and magnetic properties (Gnanajobitha et al., 2013).

Nanoparticles are defined as particulate dispersions or solid particles with a size in the range of $10-1000 \mathrm{~nm}$. The drug is dissolved, entrapped, encapsulated, or attached to a nanoparticle matrix. Depending upon the method of preparation, nanoparticles, nanospheres or nanocapsules can be obtained. In the past few years, the rapid development of nanotechnology has contributed to the production and control of engineered nanoparticles (Baek et al., 2012). The small particle size of NPs creates a large surface area per unit mass and makes them more reactive in a cell. Among the varieties of engineered nanoparticles being used today, $\mathrm{ZnO}$ NPs are one of the most widely used in consumer products. They are extensively used in cosmetics and sunscreens because of their efficient UV absorption properties. ZnO NPs are being used in the food industry as additives and in packaging due to their antimicrobial properties. They are also being explored for their potential use as fungicides in agriculture and as anticancer drugs and imaging in biomedical applications (Rasmussen et al., 2010).

NPs are not simple molecules themselves and therefore composed of three layers i.e. (a) the surface layer, which may be functionalized with a variety of small molecules, metal ions, surfactants, and polymers. (b) The shell layer, which is a chemically different material from the core in all aspects, and (c) The core, which is essentially the central portion of the NP and usually refers to the NP itself (Shin et al., 2016).

Zinc oxide $(\mathrm{ZnO})$ has unique physicochemical properties including a bright white color, the ability to block UV light, and antimicrobial activity. $\mathrm{ZnO}$ is a commonly used particle with a similar utility to $\mathrm{TiO} 2$. Also, $\mathrm{ZnO}$ is used for its antimicrobial properties and in nutritional supplements such as multivitamins. Compared with micron-sized $\mathrm{ZnO}$, nanosized $\mathrm{ZnO}$ might have better UV-blocking and antimicrobial properties and higher bioavailability (Rashidi and Khosravi-Darani, 2011). Zinc oxide nanoparticles applications are electronic industry, instrumental industry, manufacture, electrical device, radio, wireless fluorescence lamp, image recorder, rheostat, phosphor, Sun screening agent used in cosmetics, antibacterial, and health protection anti-ager; UV protection; Gas sensors; Photocatalytic decontamination; Attenuation of ultraviolet light; Demilitarization of chemical and biological warfare agents; Cosmetics and cosmeceuticals; Electrodes for solar cells; Varistors; Pigments for paints. The increased use of these particles might increase the possibility of human exposure through various routes such as inhalation, ingestion, and skin contact. In addition to uses for humans, nanomaterials are used with livestock and in the environment. Recent in vitro studies have reported that $\mathrm{ZnO}$ nanoparticles are genotoxic through the production of reactive oxygen species, although in vitro studies have limited predictive value for in vivo situations (Wiking et al., 2008).

Nowadays there is an increasing interest in the active role of herbal remedies for use in scientific research. Extracts of medicinal plants are replacing synthetic drugs. Traditional medicinal plants and spices are commonly used for their possible effects as hypoglycaemic, anti-diabetic, and folliculogenic agents instead of using synthetic drugs (Yang et al., 2010 and Rivera et al., 2014). Herbal medicine today became an important approach in solving many health problems by using traditional medicine due to its lesser sideeffects and lower costs (Falzon et al., 2017 and Zhu et al., 2017).

Foeniculum vulgare (fennel) is a medicinal plant belonging to the family Apiaceae and it is local to the Mediterranean zone as Egypt (Abdel-Moneim et al., 1997 and Senatore et al., 2013). Biochemical analysis 
of the fennel revealed its containing for high concentrations of phytoestrogens including isoflavones, coumestans, and lignans (Choi and Hwang, 2004), as well as has several medicinal properties including carminative, diuretic, expectorant, laxative, analgesic, and stimulant of gastrointestinal mobility (Khazaei et al., 2011) antispasmodic and antiinflammatory (Misharina and Polshkov, 2005). Additionally, it has antioxidant properties and the power to keep the normal activities of the liver (AlAmoudi et al., 2017). Garg et al. (2009) reported that Foeniculum vulgare is a widely distributed plant in most tropical and subtropical countries and has long been used in folk medicines to treat an obstruction of the liver, spleen, and gall bladder and for digestive complaints such as colic, indigestion, nausea, and flatulence. They are active for dyspeptic complaints, flatulence, and bloating. The volatile oil showed antioxidant, antimicrobial, and hepatoprotective activity. Fennel with a characteristic aromatic odor. It is one of the most important medicinal plants grown within the Mediterranean region. In Europe and Egypt, fennel seeds are generally eaten not only for the taste but also they are very healthy owing to the nutritional value attached to them. Fennel is also used for various health benefits that are derived from its anti-oxidants (Toma et al., 2008).

Pimpinella anisum (Anise) is a plant with white flowers and small green to yellow seeds that grow in India, Egypt, Turkey, Iran, and many other warm countries of the world. The fruits of the Anise plant that commercially called "seeds" are known as aniseed and yansoon. In folk medicine, aniseed has been used for the treatment of many diseases nausea, abdominal colic, insomnia, and epilepsy. The characteristic constituent of aniseed is trans-anethole which is responsible for its taste and smell and it is considered as an active estrogenic agent. Other constituents include coumarins, lipids flavonoids, protein, carbohydrate and minerals as calcium and phosphorus (Maofari et al., 2015). The phytotherapeutic applications of aniseed are based on its digestive, carminative, diuretic, antiseptic, and expectorating action. The principal constituents of pimpinella anisum are the anise oil (1-4\%). The major component of anise oil, trans-anethole (75-90\%), is responsible for its characteristic taste and smell and it is considered an active estrogenic agent. Other constituents include coumarins (umbelliferone, umbelliprenine, bergapten, and scopole-tin), lipids (fatty acids, beta-amyrin, and stigmasterol), flavonoids (flavonol, flavone, glycosides, rutin, isoorientin, and isovitexin), protein, carbohydrate, and minerals (calcium $646 \mathrm{mg} / 100 \mathrm{~g}$, phosphorus $440 \mathrm{mg} / 100 \mathrm{~g}$ ) (Besharati-Seidani et al., 2005 and Der Marderosian and Beutler, 2002).

The liver is the main organ responsible for xenobiotics metabolism; hence, it is vulnerable to damage induced by different chemicals. Hepatic injury is a major clinical problem associated with different xenobiotics including drugs and industrial chemicals. Hence, many hepatoprotective agents are studied to protect the liver from toxic insults (Yilmaz et al., 2013). Recently, interest in the discovery of natural antioxidants has risen exponentially. Principal candidates in this discovery process are medical plants (Sharma and Singh, 2014).

So, this study aimed to evaluate the possible treatment and protective effect of Foeniculum vulgare and Pimpinella anisum in male rats.

\section{2-Material and methods}

\section{The experimental animal}

The present work was used male albino rats (Rattus albinus) with a weight of $(150 \pm 10) \mathrm{g}$. They were purchased from the Physiology Department, Faculty of Medicine, Alexandria University, Egypt. Rats were kept individually in wire cages; acclimatization period (7 days) and also throughout all the experimental period (4 weeks).

$\mathrm{ZnO}$ NPs was obtained in the form of dispersion (Sigma-Aldrich, Steinheim, Germany). Of the following properties, concentration 50 wt. $\%$ in $\mathrm{H}_{2} \mathrm{O}$, the average nanoparticle size $<35 \mathrm{~nm}$, the particle size distribution (hydrodynamic diameter) $<100 \mathrm{~nm}$ using 
dynamic light scattering (DLS) technique, $\mathrm{pH} 7 \pm 0.1$ (for aqueous systems), and density $1.7 \mathrm{~g} / \mathrm{mL} \pm 0.1 \mathrm{~g} / \mathrm{mL}$ at $25{ }^{\circ} \mathrm{C}$. The rats were treated by $30 \mathrm{mg} / \mathrm{kg}$ for 4 weeks (El Mir et al., 2008).

\section{Preparation of plant extracts}

The seeds of F. vulgare and $P$ anisum were purchased from an herbal medicine store in Egypt. The seeds were identified by the Department of Botany of Science at the Faculty of Science, Alexandria University, Egypt. With an electrical grinder (Moulinex, France), F. vulgare and $P$ anisum seeds were grounded into powdered materials and then powdered. To get the aqueous extract of $\mathrm{F}$. vulgare, $200 \mathrm{~g}$ of the obtained powdered materials were dissolved in $800 \mathrm{~mL}$ of distilled water and then were kept in a refrigerator for $24 \mathrm{~h}$. The extract is then filtered and dried in a vacuum till obtaining $6.4 \mathrm{~g}$ of dried powder per $200 \mathrm{~g} \mathrm{~F}$. vulgare seeds. FVE was administered at a dose of $150 \mathrm{mg} / \mathrm{kg}$ diet according to European Food Safety Authority. Extraction of $P$ anisum was performed by taking $50 \mathrm{~g}$ powder in $500 \mathrm{ml}$ of distilled water for $18 \mathrm{~h}$ in the Soxhlet apparatus (Optic tech Delhi). The obtained deep brown aqueous extract was dried at reduced pressure and finally lyophilized (lyo 1580 Optic tech Delhi). This extract was used for further studies (EFSA, 2009).

\section{Experimental design}

In all groups, animals were fed their corresponding diet daily for 4 successive weeks.

Rats were divided into 4 groups of 6 rats each as follows:

Group 1 (Normal control): rats were received distilled water by gastric tube daily.

Group 2 (ZnO nanoparticles): rats have received 30 $\mathrm{mg} / \mathrm{kg}$ b.wt $\mathrm{ZnO}$ nanoparticles by gastric tube daily.

Group 3 (F. vulgare and $\boldsymbol{P}$ anisum): rats were received $150 \mathrm{mg} / \mathrm{kg}$ b.wt and $125 \mathrm{mg} / \mathrm{kg}$ b.wt, respectively by gastric tube daily.

Group 4 ( $\mathrm{ZnO}$ nanoparticles, F. vulgare and $\boldsymbol{P}$ anisum): rats were received $30 \mathrm{mg} / \mathrm{kg}, 150 \mathrm{mg} / \mathrm{kg}$ b.wt and $125 \mathrm{mg} / \mathrm{kg}$ b.wt, respectively.

\section{Collection of serum and tissue samples}

At the end of the experimental period (4 weeks) and after overnight fasting, all rats were sacrificed and blood samples were collected from the hepatic portal vein and a portion of the blood was received into a centrifuge tube and centrifuged at $1500 \mathrm{rpm}$ for $15 \mathrm{~min}$ for obtaining serum while the other portion was received into heparinized tubes and centrifuged for obtaining plasma. Serum and plasma samples were stored at $-20{ }^{\circ} \mathrm{C}$ for further assessment.

\section{Detection of liver enzymes}

Liver marker enzymes (alanine aminotransferase (ALT), aspartate aminotransferase (AST) as described by (Reitman and Frankel, 1957), and alkaline phosphatase (ALP) (Kind et al., 1954).

Detection of malondialdehyde (MDA) and catalase (CAT)

Malondialdehyde (MDA) was determined using commercial kits (Sigma-Aldrich, USA) according to (Valko et al., 2006 and Qiao et al., 2016).

\section{Detection of immunohistochemistry of interleukin 6} ((IL-6)

Interleukin 6 (IL-6) was determined using the ElISA kit (Competitive ELISA) according to (Gornall et al., 1949). Collect plasma using EDTA or heparin as an anticoagulant. Centrifuge samples for 15 minutes at $1000 \times \mathrm{g}($ or $3000 \mathrm{rpm})$ at $2-8^{\circ} \mathrm{C}$. Within 30 minutes of collection. Assay immediately or aliquot and store collection. Assay immediately or aliquot and store samples at $-20^{\circ} \mathrm{C}$ or $-80^{\circ}$.

\section{Histopathological examination}

At the end of the experiment, the rats were decapitated and livers were removed for

histopathological examination. The liver was then fixed in $10 \%$ buffered formalin solution. The fixed specimens were then trimmed, washed, and dehydrated in ascending grades of alcohol, cleared in xylene, embedded in paraffin, and sectioned at 4-6 $\mu$ thickness and stained with Haematoxylen and Eosin as a routine stain.

\section{Statistical analysis}


All values were expressed as mean \pm standard error (SE). The differences were analyzed using one-way analysis of variance (ANOVA). The P-value $<0.05$ reflects significant differences.

\section{3-Results}

\section{Effect on biochemical parameters}

In the present study $\mathrm{ZnO}$ nanoparticles when injected 4 weeks in male rats caused hepatotoxicity as evident from Table 1 , showing a significant increase $(p \leq 0.05)$ in liver marker enzymes activities of ALT, AST, and ALP in the serum of the animals which treated orally by $\mathrm{ZnO}$ nanoparticles as compared to control group. The group treated with Foeniculum vulgare and Pimpinella anisum showing a significant decrease in the levels of ALT, AST, and ALP when compared to the $\mathrm{ZnO}$ nanoparticles group. Co-treatment of Foeniculum vulgare, Pimpinella anisum, and $\mathrm{ZnO}$ nanoparticles in the combination group caused a significant decrease in the mean values of ALT, AST, and ALP in the serum when compared to $\mathrm{ZnO}$ nanoparticles.

\section{Effect of Foeniculum vulgare, Pimpinella anisum on the Activity of Lipid Peroxidation and Antioxidant Enzymes in the serum}

The biochemical changes lipid peroxidation antioxidant enzymes were studied on the serum of rats (Table 1). There was a significant increase $(p \leq 0.05)$ in MDA level in the $\mathrm{ZnO}$ nanoparticles group when compared to the control ones. After treatment, the rats with Foeniculum vulgare and Pimpinella anisum showed a significant decrease $(p \leq 0.05)$ when compared to the $\mathrm{ZnO}$ nanoparticles group as well as the presence of aqueous extracts of Foeniculum vulgare and Pimpinella anisum with $\mathrm{ZnO}$ nanoparticles in combination group minimized its effect compared to $\mathrm{ZnO}$ nanoparticles alone. There was a significant decrease $(p \leq 0.05)$ in the CAT activity in the $\mathrm{ZnO}$ nanoparticles group when compared to control rats. The activity of the CAT enzyme showed a significant increase in the group treated by Foeniculum vulgare, Pimpinella anisum, and $\mathrm{ZnO}$ nanoparticles when compared to control, $\mathrm{ZnO}$ nanoparticles, and fennel+anism groups $(\mathrm{p} \leq 0.05)$.

\section{Immunohistochemistry investigation in the serum}

The concentration of interleukin- 6 was recorded in the group treated by $\mathrm{ZnO}$ nanoparticles significant increase ( $p \leq 0.05$ ) when compared to control rats. The group treated by fennel+anism has a significant decrease when compared to the $\mathrm{ZnO}$ nanoparticles group. The presence of Foeniculum vulgare and Pimpinella anisum with $\mathrm{ZnO}$ nanoparticles in the combination group decreased the level of plasma interleukin- 6 but did not reach the values of a control group.

\section{Histopathological Investigation of Liver Tissues}

A section of the liver tissue from the control group has shown the normal histological structure of the hepatic lobule and central vein without alterations as shown in Figure 4 A. Additionally, the hepatocytes were arranged in the form of branching cords and appeared irregular polygonal or polyhedral shaped cells typically with a single, central, large vesicular nucleus. Some binucleated cells were occasionally observed, occupying a central position of the hepatocytes. The cord is separated by blood sinusoids and radiated from the central vein. In contrast, the liver tissue of the $\mathrm{ZnO}$ nanoparticles group, exhibited in Figure 4 (B), has shown several alterations clear signs of severe hepatic injury including activation of Kupffer cells, the formation of degenerated areas of destroyed hepatocytes that lost their normal characters and were fused, presence of some vacuoles, marked dilation and congestion of hepatic sinusoids. Interestingly, liver tissue in the $\mathrm{ZnO}$ nanoparticles group treated with Foeniculum vulgare and Pimpinella anisum, displayed in Figures 4 (C, D) exhibited apparent normal histological structure. 
Table (1) Effect of Foeniculum vulgare and Pimpinella anisum on the activities of ALT, AST, ALP, MDA, CAT, and interleukin-6 in the serum $(X \pm$ S.E).

\begin{tabular}{|c|c|c|c|c|}
\hline parameters & $\begin{array}{l}\text { Control } \\
\text { Gp }\end{array}$ & $\begin{array}{l}\text { Zno } \\
\text { gp }\end{array}$ & fennel+anism gp & Zno+fennel+anism gp \\
\hline ALT (U/ml) & $36.33 \pm 0.8 b$ & $41 \pm 0.5 c$ & $21.6 \pm 2.7 a$ & $32.6 \pm 1.7 b$ \\
\hline $\operatorname{AST}(\mathrm{U} / \mathrm{ml})$ & $69.3 \pm 1.2 \mathrm{a}$ & $115 \pm 4.0 \mathrm{c}$ & $86.3 \pm 3.4 b$ & $89.3 \pm 4.0 b$ \\
\hline $\operatorname{ALP}(\mathbf{U} / \mathbf{L})$ & $152.6 \pm 1.7 a$ & $362.6 \pm 50.5 b$ & $130 \pm 2.8 a$ & $211.6 \pm 5.4 a$ \\
\hline MDA (nmolml) & $5.6 \pm 0.18 a$ & $28.0 \pm 2.6 c$ & $5.6 \pm 0.40 \mathrm{a}$ & $14.2 \pm 1.50 b$ \\
\hline CAT (UIL) & $9.03 \pm 0.3 b$ & $7.2 \pm 0.3 a$ & $11.9 \pm 0.7 b$ & $13.2 \pm 0.5 b$ \\
\hline $\begin{array}{l}\text { Interleukin-6 } \\
(\mathrm{pg} / \mathrm{ml})\end{array}$ & $85 \pm 1.1 a$ & $135.6 \pm 3.1 \mathrm{c}$ & $88 \pm 1.7 a$ & $112 \pm 6.2 b$ \\
\hline
\end{tabular}



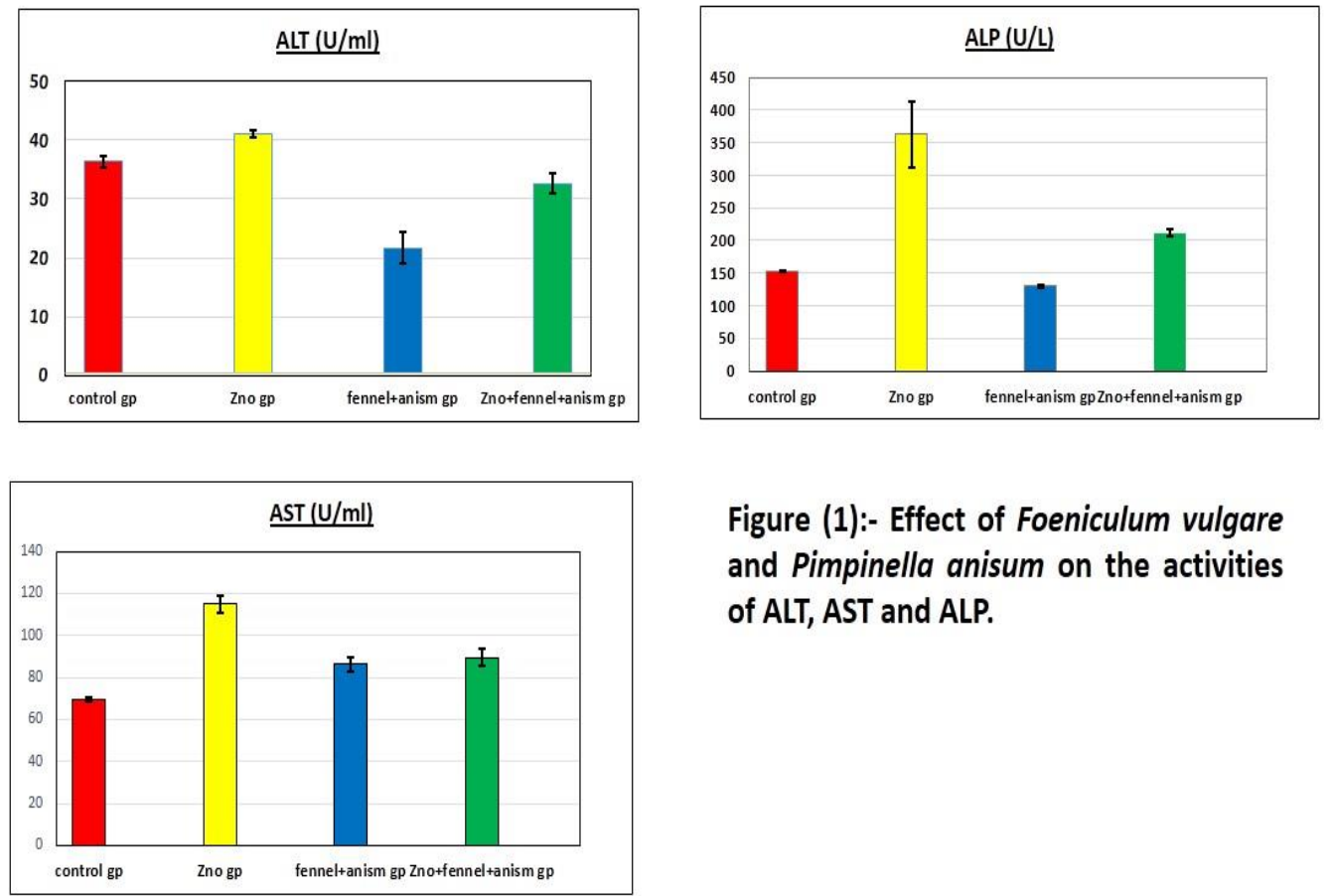

Figure (1):- Effect of Foeniculum vulgare and Pimpinella anisum on the activities of ALT, AST and ALP.
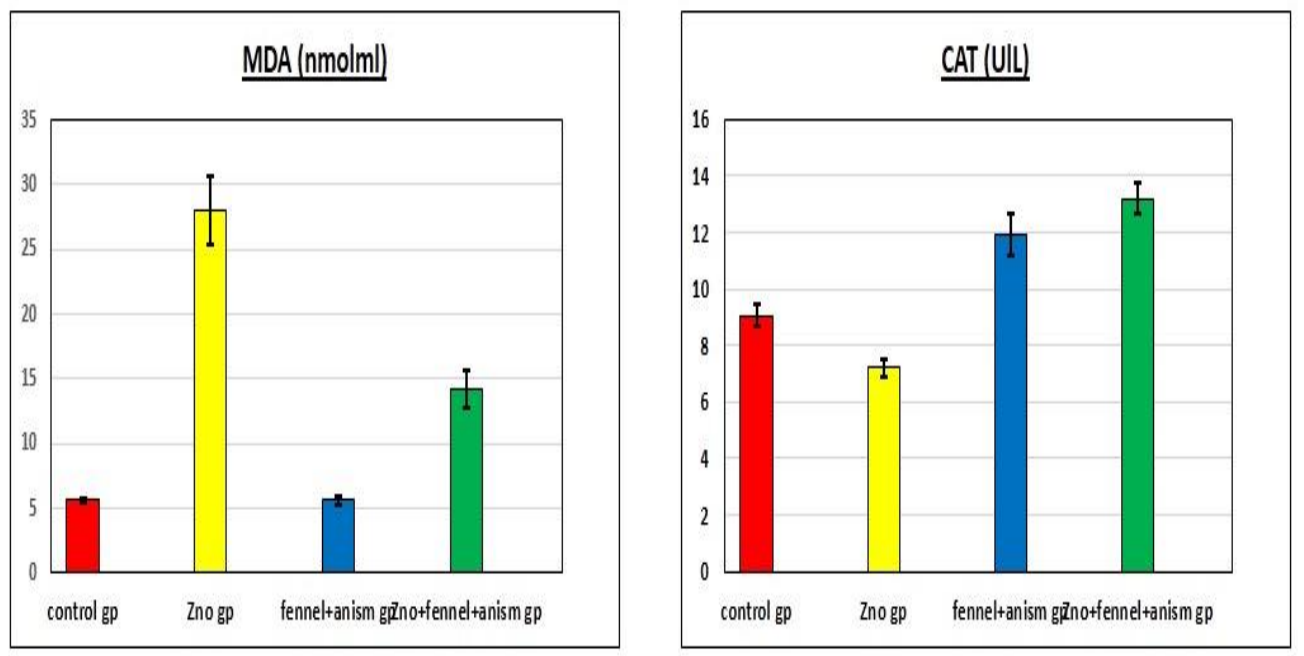

Figure (2):- Effect of Foeniculum vulgare and

Pimpinella anisum on the activities MDA and CAT 


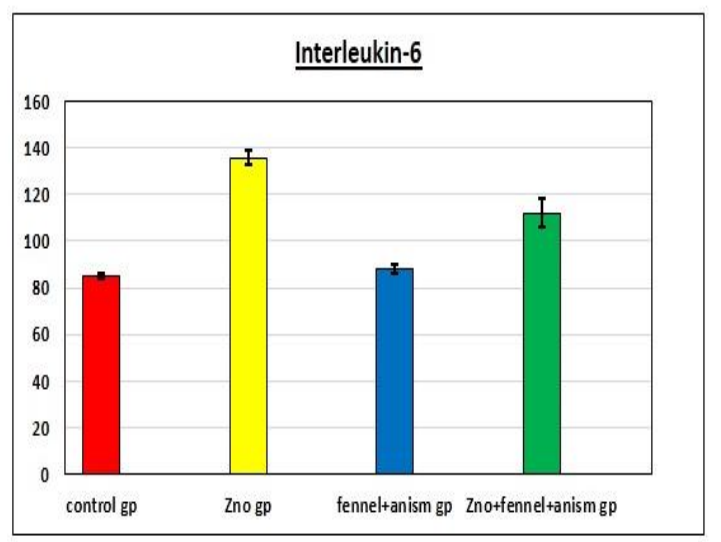

Figure (3):- Effect of Foeniculum vulgare and Pimpinella anisum on the activity of Interleukin-6

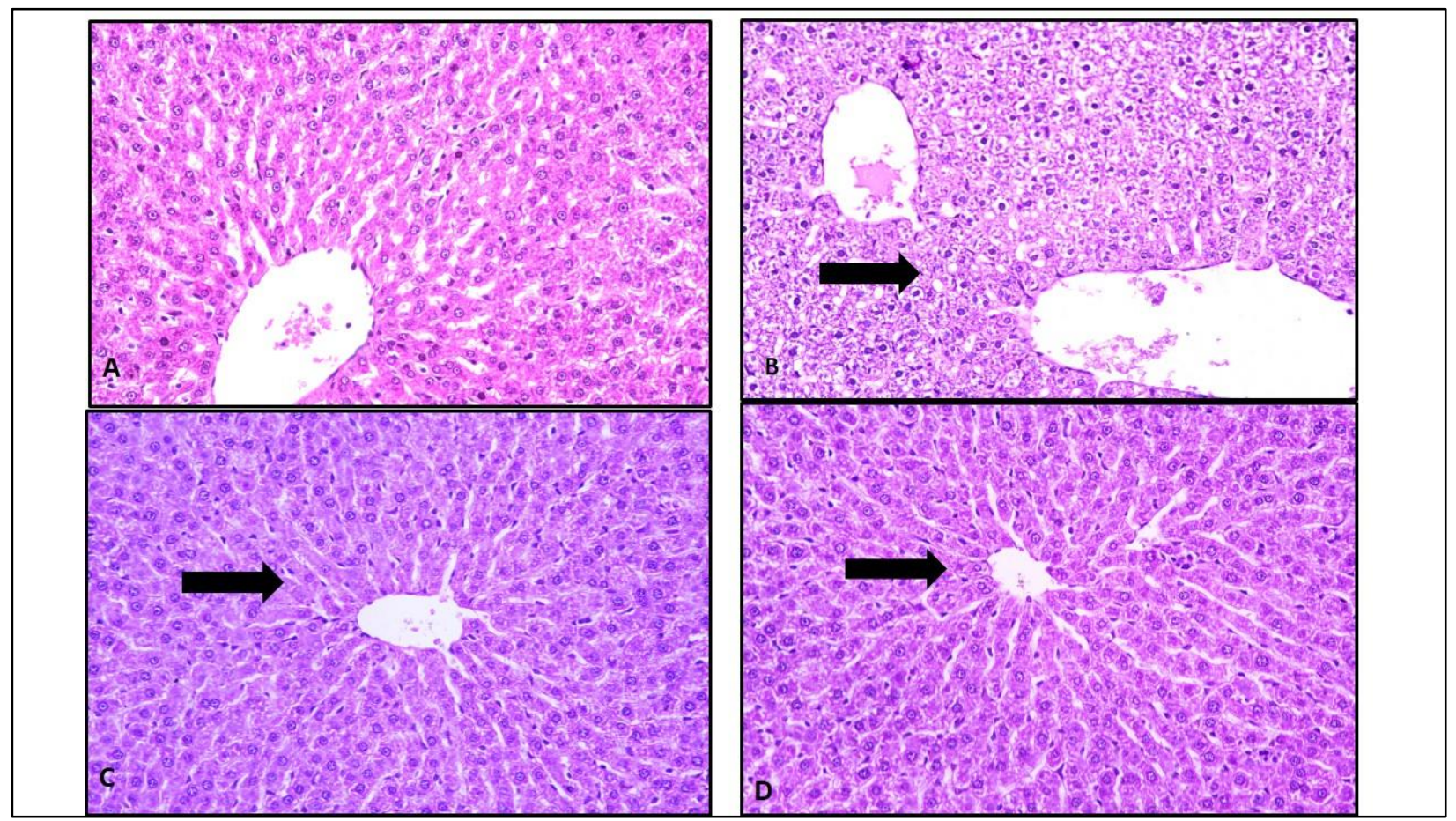

Figure 4:- Photomicrographs of a section in the liver tissue of the A) control group showing the normal structure, central vein (CV), normal arrangement of hepatic cords, normal blood sinusoids (S), hepatocytes (H), and Kupffer cells (KP), and $\mathrm{B}$ ) $\mathrm{ZnO}$ nanoparticles group showing dilated and congested central vein (CV), congestion and dilation blood sinusoids (S), activation of Kupffer cells (KP), degeneration of some hepatocytes (H) and hepatocyte vacuolization (V) C and D) exhibited apparent normal histological structure (H\&E X 400). 


\section{4-Discussion}

The liver is a vital organ that plays an important vital function in metabolism, maintenance, performance, and regulating the homeostasis of the body and excretion of xenobiotics from the body. It is involved with almost all the biochemical pathways to growth, fight against disease, nutrient supply, energy provision, and reproduction. And its functions as a center of metabolism of nutrients such as carbohydrates, proteins, and lipids and excretion of waste metabolites. Therefore, maintenance of a healthy liver is essential for the overall well-being of an individual (Sharma and Singh, 2014).

$\mathrm{ZnO}$ nanoparticles are well known to have a high toxicity. One of the mechanisms of this toxicity is their ionization in biological fluids. Combined with toxicity data, kinetics data can provide the actual concentration of nanoparticles as they interact with biological systems. However, compared with other routes of administration, kinetics data following the oral administration of nanoparticles is limited. Humans have a higher chance of being exposed to $\mathrm{ZnO}$ nanoparticles in food-related products than other nanoparticles. Therefore, further evaluation of the tissue distribution and absorption of these nanoparticles following oral administration is needed to provide valuable information for assessing the risk of these nanoparticles (Rincker et al., 2005). With the increased use of $\mathrm{ZnO}$ NPs exposure to these nanoparticles has been rising steadily, resulting in more attention being paid to their potential toxicity, including cytotoxic, genotoxic, and proinflammatory effects (Hackenberg et al., 2011 and Teow et al., 2011). Nanoscale particles can enter the human body through different routes such as inhalation, ingestion, and injection. They may then translocate to blood causing adverse biological reactions in several organs (Johnston et al., 2011).
Some researchers consider that $\mathrm{ZnO}-\mathrm{NPs}$ as a material of low toxicity because zinc is an essential trace element in the human body and is commonly present in foods or added as a nutritional supplement, so zinc attracts little attention during an assessment of the toxicity of nanoparticles (Wang et al., 2008). On the other hand, it is known that a high concentration of zinc is responsible for toxic effects. Several studies have reported that $\mathrm{ZnO}$ nanoparticles at a high dose of 1-5 $\mathrm{g} / \mathrm{kg}$ can cause apoptosis in liver cells and induce severe oxidative stress. Moreover, recent studies have demonstrated that $\mathrm{ZnO}-\mathrm{NPs}$ are toxic to microorganisms and rodents. $\mathrm{Zn}^{2+}$ are the main causes of toxicity (Pujalté et al., 2011). Preliminary results indicated that affected organ systems may show inflammation and oxidative stress (Campbell et al., 2005). Ingested nanoparticles may be absorbed through the intestinal lining and translocate into the bloodstream where they undergo the first-pass metabolism in the liver (Böckmann et al., 2000). Again, the effects of this translocation are largely unknown. Biodistribution experiments have revealed the liver as the target organs for engineered nanoparticles after uptake by the gastrointestinal tract (Cui et al., 2011).

F. vulgare and $P$ anisum plants have a long history of use in herbal medicine due to their antioxidant activity. Thus, this study aimed to investigate the effects of FVE and $P$ anisum against $\mathrm{ZnO}$ nanoparticles induced hepatic and immunohistochemistry disturbance. The data of the current study clarified that administration of $\mathrm{ZnO}$ nanoparticles induced severe structural damage in the liver cells. The hepatocytes appeared irregularly arranged with disorganization of hepatic architecture. The central vein appeared dilated and congested. Mild fibrosis was exhibited around the bile duct in the portal area. It was evidenced that the activities of ALT, AST, and ALP in the serum of rats are tested as biomarker 
enzymes for normal hepatic function these results are in agreement with (El-Sheikh and Galal, 2015). Increased the damage of the membrane coat of hepatocytes which consequently leads to leakage of these enzymes from the cytoplasm into the blood circulation and finally increases significantly the serum levels of ALT, AST, and ALP enzymes. High levels of AST are commonly observed with viral or cardiac infarction induced-liver damage (Sallie et al., 1991).

The oral administration of a moderate dose of $\mathrm{ZnO}-\mathrm{NPs}$ $(10 \mathrm{mg} / \mathrm{kg})$ induced a marked increase in plasma AST and ALT enzymes. From our results, we can deduce that the elevated levels of transaminases, which are located primarily in the cytosol of hepatocytes, is a sign of damage that leads to liver dysfunction in treated rats. These biochemical findings were supported by histopathology examination, which showed signs of cytotoxicity (inflammatory response, vascular congestion, and edema formation) in rat liver. This is in agreement with a previous report indicating that subacute oral exposure to $\mathrm{ZnO}$ nanoparticles $(3 \mathrm{mg} / \mathrm{kg}$ ) for 30 consecutive days induced hepatocellular necrosis (Soheili et al., 2013). Therefore, the remarkable histopathological changes in hepatic tissues together with the elevated hepatic enzymes reported in the current study proved the hepatotoxic effects of $\mathrm{ZnO}$ nanoparticles treatment (Ben-Slama et al., 2015). On the contrary, and FVE improved liver functions and maintain a normal level of liver enzymes (ALT and AST). Moreover, their co-administration with $P$ anisum restored the level of ALT and AST enzymes to normal values. These results were supported by the positive histopathological findings from this study. It was found that FVE and anism maintained normal liver architecture as well as partially ameliorated the damage induced by $\mathrm{ZnO}$ nanoparticles administration.
The free radical damage occurred in tissues by two mechanisms: Increased generation of reactive oxygen species (ROS), including hydroperoxides, singlet oxygen, and hydrogen peroxides, and by causing direct depletion of antioxidant reserves (Owoeye and Onwuka, 2016). Fennel contains its unique combination of phytonutrients-including the flavonoids rutin, quercetin, and various kaempferol glycosidesthat give it strong antioxidant activity (Shaffie et al., 2010). The major chemical components of fennel are flavonoids, polyphenols, carotenoids, minerals, and vitamins (Koppula and Kumar, 2013). Fennel is used as a carminative, digestive, lactogogue, diuretic, and in treating respiratory and gastrointestinal disorders. Pharmacologically, fennel has been shown to possess anti-inflammatory, anti-diabetic, anti-bacterial, antifungal, anti-oxidant, analgesic, estrogenic, hepatoprotective, anti-tumor activities. Also, it is used as an herbal medicine for kidney diseases (Chatterjee et al., 2012).

The present data showed that there was an increase in MDA concentration as an indicator of lipid peroxidation and a decrease in the level of CAT level as a marker of oxidative stress in the group treated by $\mathrm{ZnO}$ nanoparticles for 4 weeks. Nanoparticles mediated toxicity includes oxidative stress, inflammation, genetic damage, and the inhibition of cell division and cell death (Johnston et al., 2010). Most work to date has suggested that ROS generation (which can be either protective or harmful during biological interactions) and consequent oxidative stress are frequently observed with NP toxicity. Reactive oxygen species (ROS) are constantly generated in vivo for physiological purposes. Their productions are often balanced by an antioxidant defense system. However, excess Reactive oxygen species (ROS) production beyond the ability of the antioxidant defense system can cause oxidative damage to protein, lipid, and 
nucleic acid. Antioxidant defense includes antioxidant enzymes such as superoxide dismutase (SOD), catalase (CAT), and glutathione peroxidase (GPx), in addition to low molecular agents and dietary antioxidants. Disturbing of oxidant balance system is involved in the development of many chronic diseases such as atherosclerosis, cancer, and diabetes (Govindarajan et al., 2005).

The physicochemical characterization of nanoparticles including particle size, surface charge, and chemical composition is a key indicator for the resulting ROS response and NP-induced injury since many of these NP intrinsic properties can catalyze the ROS production (Shvedova et al., 2012). Another NP such as titanium dioxide $(\mathrm{TiO} 2)$, zinc oxide $(\mathrm{ZnO})$, and silver NP has been shown to deposit on the cell surface or inside the subcellular organelles and induce oxidative stress signaling that eventually result in oxidative stress to the cell (Buzea et al., 2006). ZnO NP has been reported to influence intracellular calcium concentrations, activate transcription factors, and modulate cytokine production via the generation of free radicals. Extremely toxic levels of oxidative stress result in mitochondrial membrane damage and electron chain dysfunction leading to cell death (Huang et al., 2010). Given its chemical reactivity, oxidative stress can amount to DNA damage, lipid peroxidation, and activation of signaling networks associated with loss of cell growth, fibrosis, and carcinogenesis (Buzea et al., 2007\& Valko et al., 2006). Inflammatory phagocytes are an important source of RNS/ROS generation. Owing to their inducible nitric oxide synthase (iNOS) activity, phagocytes can produce a large amount of genotoxic RNS, including nitric oxide (NO·) and the highly reactive peroxynitrite (ONOO-). ONOOformed by the reaction of $\mathrm{NO}$ and $\mathrm{O}_{2}$ - $^{-}$causes DNA fragmentation, lipid oxidation, and protein dysfunction. The toxicity of metallic NP including $\mathrm{Zn}, \mathrm{Ti}, \mathrm{Si}, \mathrm{Fe}$, and
Ce has been characterized by increased ROS generation and oxidative stress, and apoptosis. DNA is one of the major targets for oxidative stress and represents the first step involved in mutagenesis, carcinogenesis, and aging. ROS/RNS causes oxidative DNA damage in the form of DNA strand breaks (Naqvi et al., 2010). Testing the genotoxic potential is essential for carcinogenic risk assessment of NP. Genotoxic effects may be produced either by direct interaction of particles with genetic material or by secondary damage from particle-induced ROS. Transition metal NP induces chromosomal aberrations, DNA strand breaks, oxidative DNA damage, and mutations (Eblin et al., 2006). Along with chromosomal damage, free radicals also interact with lipids and proteins, abundantly present in biomembranes, to yield lipid peroxidation products associated with mutagenesis (Knaapen et al., 2004). Prooxidant metals such as $\mathrm{Cu}$ and $\mathrm{Fe}$ react with these lipid hydroperoxides to induce DNA damaging end-products malondialdehyde (MDA) and 4hydroxynonenal that act as inflammatory mediators and risk factors for carcinogenesis Exposures to $\mathrm{ZnO}$ $\mathrm{NP}$ of $\mathrm{Ti}, \mathrm{Cu}, \mathrm{Si}$, and $\mathrm{Fe}$ were reported to induce tissue damage, abnormal cellular stress response via lipid peroxidation (Shukla et al., 2010). Alterations within the antioxidant defense system pose as a risk factor for carcinogenesis (Li et al., 2008). NP-triggered free radicals CAT thereby contributing to oxidative stress, apoptosis, and sensitization to oxidizing stimuli on the other hand Catalase (CAT) is known for its involvement in detoxifying the high hydrogen peroxide $\left(\mathrm{H}_{2} \mathrm{O}_{2}\right)$ concentrations (Fenoglio et al., 2008). Apart from GSH, NP-induced ROS modulate the antioxidant activities of ROS-metabolizing enzymes including NADPH-dependent flavor enzyme, catalase, glutathione peroxidase, and superoxide dismutase. It is well established that uncontrolled generation of ROS triggers a cascade of proinflammatory cytokines and 
mediators via activation of redox-sensitive MAPK and $\mathrm{NF}-\kappa \mathrm{B}$ signaling pathways that control transcription of inflammatory genes such as IL- $1 \beta$, IL-8, and TNF- $\alpha$ (De Berardis et al., 2010). These results were in agreement with the present study there was an increase in the concentration of interleukin-6 in the group treated with $\mathrm{ZnO}$ nanoparticles. Oxidative stress plays a key role in NP-induced airway hypersensitivity and respiratory inflammation. $\mathrm{ZnO}$ nano induces an elevated inflammatory response through the underlying mechanism of ROS generation (Kumar et al., 2011). Reactive oxygen species (ROS) may produce cellular injury and necrosis via, several mechanisms including peroxidation of membrane lipids, protein denaturation, and DNA damage (Arivazhagan and Vimaastalin, 2014). The present study recorded that the treatment of rats by Pimpinella anisum moderated the concentration of CAT and MDA as control rats. Several experimental studies have shown the antioxidant potential of Pimpinella anisum (Shobha and Andallu, 2015). As well fennel contains a mixture of bioactive compounds as well as essential trace elements that could be of value to stimulate the body's self-defense mechanisms against oxidative stress. Phytochemical screening of aniseed has revealed polyphenolic compounds like flavonoids, tannins, and phenolic acids as major components. These are very vital for the free-radical scavenging and antioxidant activities of plants as they act as hydrogen donors and thus neutralize the freeradicals as assessed by DPPH and ABTS radical scavenging activity assays. This radical scavenging potential of aniseed extract can also be supported by significantly decreased lipid peroxidation in the in vitro models. Moreover, its antioxidant activity has also been partially held responsible for its preventive and therapeutic effects on acute hepatic injury in rats. The above properties of aniseed can protect biomolecules like proteins, nucleic acids, polyunsaturated fatty acids in membranes and prevent most of the biological molecules from oxidation, thus decreasing the rate of lipid peroxidation (Aiswarya et al., 2018).

The antioxidant properties of water and ethanolic extracts of aniseeds were evaluated using different antioxidant tests, and antioxidant activities were compared with synthetic antioxidants such as butylated hydroxyanisole (BHA), butylated hydroxytoluene (BHT), and $\alpha$-tocopherol. Both extracts of aniseeds showed strong antioxidant activity, reducing power, DPPH radical and superoxide anion scavenging, hydrogen peroxide scavenging, and metal chelating activities compared to BHA, BHT, and $\alpha$-tocopherol, and water extract exhibited greater antioxidant capacity than ethanolic extract (Akhtar et al., 2008). As well as the high concentration of reactive oxygen species produced by $\mathrm{ZnO}$ nanoparticles and resulted in severe oxidative stress. In this respect, it was evidenced that $\mathrm{ZnO}$ nanoparticles induced a significant decrease in enzymatic antioxidant activities and a significant increase of $\mathrm{H}_{2} \mathrm{O}_{2}$ and MDA which suggest the higher oxidative stress of nanoparticles in animal cells (Tribowo et al., 2014). In the current study, $\mathrm{ZnO}$ nanoparticles administration elevated the serum level of MDA and lowered the serum level of CAT in comparison to the control group. Thus, it was suggested that the protective effect of Foeniculum vulgare (fennel) and Pimpinella anisum (anism) against $\mathrm{ZnO}$ nanoparticles toxicity in the liver is contributed to their potent antioxidant activity. The potent antioxidant activities of (fennel) and (anism) are previously reported. This protective effect due to their antiinflammatory properties (Choi and Hwang, 2004) \& (Khazaei et al., 2011). Moreover, some active components present in fennel seeds extracts, including flavonoids, polyphenols, and carotenoids have antioxidant, anti-inflammatory, and free radicals 
scavenging activity (Rabeh and Aboraya, 2014) \&(El

Baz et al., 2014).

\section{5-References}

Abdel-Moneim A, El-Feki M, Salah E. (). Effect of Nigella sativa oil and gliclazide on alloxan diabetic rats, biochemical and histopathological studies. J Egypt Ger Soc Zool 1997; 23: 237-265.

Aiswarya N, Rashmi RR, Preethi JS, Chandran V, Teerthanath S, Sunil PB, Rakesh KB. Nephroprotective Effect of Aqueous Extract of Pimpinella anisum in Gentamicin Induced Nephrotoxicity in Wistar Rats. Pharmacog J. 2018; 10(3):403-407.

Akhtar, A. Deshmukh, A. A. Bhonsle A. V., et al., "In vitro Antibacterial activity of Pimpinella anisum fruit extracts against some pathogenic bacteria," Veterinary World, 2008; vol. 1, no. 9, pp. 272274 .

Al-Amoudi WM. Protective effects of fennel oil extract against sodium valproate-induced hepatorenal damage in albino rats. Saudi J Biol Sci 2017; 24: 915-924.

Arivazhagan SJJ, Vimaastalin R. Nephroprotective activity of Aristo lochia Indica leaf extract against gentamicin-induced renal dysfunction. International Journal of Research in Biochemistry and Biophysics. 2014; 4(2):13-8.

Baek M, Chung HE, Yu J, Lee JA, Kim TH, et al. Pharmacokinetics, tissue distribution, and excretion of zinc oxide nanoparticles. Int $\mathrm{J}$ Nanomedicine 2012; 7: 3081-3097.

Ben-Slama I, Mrad I, Rihane N, Mir LE, Sakly M, et al. Sub-Acute Oral Toxicity of Zinc Oxide Nanoparticles in Male Rats. J Nanomed Nanotechnol 2015; 6: 284.

Besharati-Seidani A, Jabbari A, Yamini Y: Headspace solvent microextraction: a very rapid method for identification of volatile components of Iranian Pimpinella anisum seed. Anal Chim Acta 2005; 530:155-161.

Böckmann J, Lahl H, Eckert T, Unterhalt B. [Titanium blood levels of dialysis patients compared to healthy volunteers]. Pharmazie 2000; 55: 468.

Buzea, C. Pacheco, I. I., and K. Robbie, "Nanomaterials and nanoparticles: sources and toxicity," Biointerphases, 2007; vol. 2, no. 4, pp. MR17-MR71.

Campbell A, Oldham M, Becaria A, Bondy SC, Meacher D, et al. Particulate matter in polluted air may increase biomarkers of inflammation in mouse brain. Neurotoxicology 2005; 26: 133140.

Chatterjee S., Goswami N. and Bhatnagar P. Estimation of Phenolic components and in vitroantioxidant activity of Fennel (Foeniculum vulgare) and Ajwain (Trachyspermumammi) seeds, Adv Biores. 2012; 3 (2): 109 - 18.

Choi E, Hwang J. Anti-inflammatory, analgesic and antioxidant activities of the fruit of Foeniculum vulgare. Fitoterapia 2004; 75(6): 557-565.

Cui Y, Liu H, Zhou M, Duan Y, Li N, et al. Signaling pathway of inflammatory responses in the mouse liver caused by $\mathrm{TiO} 2$ nanoparticles. J Biomed Mater Res A 2011; 96: 221-229.

Der Marderosian AH, Beutler JA: Facts and Comparisons. In The review of natural products: the most complete source of natural product information St. Louis; 2002; 301-468.

Eblin, K. E. Bowen, M. E. Cromey D. W. “Arsenite and mono methyl arsonous acid generate oxidative stress response in human bladder cell culture," Toxicology and Applied Pharmacology, 2006; vol. 217 , no. 1 , pp. 7-14. 
El-Baz F.K., Salama Z.A., Abdel Baky H.H., Gaafar

A.A. Hepatoprotective effect of sweet Fennel (Foenculum vulgare L.) methanol extract against carbon tetrachloride induced liver injury in rats, Int J Pharm Sci Rev Res. 2014; 25(2): 194-201.

El Mir L, Amlouk A, Barthou C, Alaya S. Synthesis and luminescence properties of $\mathrm{ZnO} / \mathrm{Zn} 2 \mathrm{SiO} 4 / \mathrm{SiO} 2$ composite based on nanosized zinc oxide confined silica aerogels Condensed Matter. Physica B 2008; 388:412.

El-Sheikh EA, Galal AA. Toxic effects of sub-chronic exposure of male albino rats to emamectin benzoate and possible ameliorative role of Foeniculum vulgare essential oil. Environ Toxicol Pharmacol 2015; 39(3): 1177-1188.

European Food Safety Authority (EFSA). Advice on the EFSA guidance document for the safety assessment of botanicals and botanical preparations intended for use as food supplements, based on real case studies. EFSA J 2009; 7: 280.

Fenoglio NI., Corazzari, I., Francia C, Bodoardo S., Fubini, B. "The oxidation of glutathione by cobalt/tungsten carbide contributes to hard metal-induced oxidative stress," Free Radical Research, 2008; vol. 42, no. 8, pp. 737-745.

Garg C, Khan S, Ansari S, and Suman A: Chemical composition, therapeutic potential and perspectives of fennel. J. of Phcog. Rev., 2009; 3 (6): 46- 52.

Ge Y, Schimel JP, Holden PA: Identification of soil bacteria susceptible to $\mathrm{TiO} 2$ and $\mathrm{ZnO}$ nanoparticles. Appl Environ Microbiol 2012, 78(18):6749-6758.

Gornall, A.G. Bardawill, C. J., David, M. M.

Determination of serum protein By mean of the biuret reaction. The Journal of Biological

Chemistry 1949; 177: 751-265.

Govindarajan R, Vijayakumar M, Pushpangadan P: Antioxidant approach to disease management and the role of 'Rasayana' herbs of Ayurveda. Journal of ethnopharmacology 2005, 99(2):165178.

Hackenberg S, Zimmermann FZ, Scherzed A, Friehs G, Froelich K, et al. Repetitive exposure to zinc oxide nanoparticles induces DNA damage in human nasal mucosa mini organ cultures. Environ Mol Mutagen 2011; 52: 582-589.

Huang, C. Aronstam, R. S. Chen, D. and Y. Huang, "Oxidative stress, calcium homeostasis, and altered gene expression in human lung epithelial cells exposed to $\mathrm{ZnO}$ nanoparticles, "Toxicology in Vitro, 2010; vol. 24, no. 1, pp. 45-55.

Johnston, H. J. Hutchison, G. Christensen, F. M. Peters, S. S. Hankin, Stone, V. "A review of the in vivo and in vitro toxicity of silver and gold particulates: particle attributes and biological mechanisms responsible for the observed toxicity," Critical Reviews in Toxicology, 2010; vol. 40, no. 4, pp. 328-346.

Khazaei M, Montaseri A, Khazaei MR, Khanahmadi M. Study of Foeniculum vulgare effect on folliculogenesis in female mice. Int J Fertil Steril 2011; 5: 122-127.

Kind, P.R.N. and King, E.J.: Estimation of plasma phosphatase determination of hydrolyzed phenol with amino-antipyrine. J. Clini. Pathol. 1954; 7: 322-326.

Knaapen, A. M., Borm, P. J. A., Albrecht, C., Schins, R. P. F "Inhaled particles and lung cancer, partA: mechanisms," International Journal of Cancer, 2004; vol. 109, no. 6, pp. 799-809.

Koppula S. and Kumar H. Foeniculum vulgare mill (Umbelliferae) attenuates stress and 
improves memory in Wister rats, Trop J Pharm Res. 2013; 12 (4): 553-8.

Kumar, A. Pandey, A. K.. Singh, S. S Shanker, R. Dhawan, A. "Engineered $\mathrm{ZnO}$ and $\mathrm{TiO} 2$ nanoparticles induce oxidative stress and DNA damage leading to reduced viability of Escherichia coli," Free Radical Biology and Medicine, 2011; vol. 51, no. 10, pp. 18721881.

Li N. De Berardis B., Civitelli, G. Condello M.et al., "Exposure to $\mathrm{ZnO}$ nanoparticles induces oxidative stress and cytotoxicity in human colon carcinoma cells," Toxicology and Applied Pharmacology, 2010; vol. 246, no. 3, pp. 116-127.

Maofari AA, Hajjaji SE, Zaydoun S, Ouaki B, Charof $\mathrm{R}$, et al. The Chemistry Characterization and Activity Antibacterial of Different Extracts of Anise. International Journal of Engineering \& Technology IJET-IJENS 2015; 15(1): 34-38.

Misharina TA, and Polshkov A N: Antioxidant properties of essential oils: autooxidation of essential oils grom laurel and fennel and effects of mixing with essential oil from coriander, Prikl. Bioch. Micro, 2005; 41(6): 693-702.

Naqvi, S. Samim, M. Abdin M. Z., et al., "Concentration dependent toxicity of iron oxide nanoparticles mediated by increased oxidative stress," International Journal of Nanomedicine, 2010; vol. 5, no. 1, pp. 983989.

Owoeye O. and Onwuka S.K. Lead Toxicity: Effect of Launaeataraxacifolia on the histological and oxidative alterations in rat regio III cornuammonis and cerebellum, Anatomy Journal of Africa. 2016; 5(1):783-94.
Pujalté I, Passagne I, Brouillaud B, Tréguer M, Durand $\mathrm{E}$, et al. Cytotoxicity and oxidative stress induced by different metallic nanoparticles on human kidney cells. Part Fibre Toxicol 2011; 8: 10 .

Qiao YF, Guo W, Li L, Shao S, Qiao X, Shao J, et al. Melatonin attenuates hypertension-induced renal injury partially through inhibiting oxidative stress in rats. Mol Med Rep 2016; 13: 21-26.

Rabeh N.M. and Aboraya A.O. Hepatoprotective effect of dill (Anethumgraveolens L.) and Fennel (Foeniculum vulgare) oil on hepatotoxic rats, Pak J Nut. 2014; 13 (6): 303-9.

Rashidi L, Khosravi-Darani K. The applications of nanotechnology in food industry. Crit Rev Food Sci Nutr, 2011; 51(8):723-730.

Rasmussen JW., Martinez E., Louka P, Wingett DG (). Zinc oxide nanoparticles for selective destruction of tumor cells and potential for drug delivery applications. Expert Opin Drug Deliv 2010; 7: 1063-1077.

Reitman B, Frankei A. Colorimetric method for the determination of serum glutamic oxalacetic and glutamic pyruvic transaminases. Am J Clin Pathol 1957; 28(1): 56-63.

Rincker MJ, Hill GM, Link JE, Meyer AM, Rowntree JE: Effects of dietary zinc and iron supplementation on mineral excretion, body composition, and mineral status of nursery pigs. J Anim Sci 2005, 83(12):2762-2774.

Rivera J.O., Loya A.M., and Ceballos R. Use of Herbal Medicines and Implications for Conventional Drug Therapy Medical Sciences. Alternative and Integrative Medicine; 2014; 3:2-6.

Sallie R, Tredger JM, Williams R. Drugs, and the liver. Biopharm Drug Dispos 1991; 12: 251-259. 
Senatore F, Oliviero F, Scandolera E, TaglialatelaScafati O, Roscigno G, Zaccardelli M, et al. Chemical composition, antimicrobial and antioxidant activities of anethole-rich oil from leaves of selected varieties of fennel [Foeniculum vulgare Mill. ssp. Vulgare var. azoricum (Mill.) Thell]. Fitoterapia 2013; 90: 214-219.

Shaffie M.N., Morsy A.F., Ali G.A. and Sharaf A.H. Effect of Craway, Coriander and Fennel on the structure of kidney and islets of Langerhans in alloxan-Induced diabetic rats: Histological and histochemical study, Researcher. 2010; 2 (7): $27-40$

Sharma V, Singh M. Attenuation of N-nitrosodimethylamine induced hepatotoxicity by Operculina turpethum in Swiss Albino mice. Iran J Basic Med Sci 2014; 17:73-80.

Shin, W.-K., Cho, J., Kannan, A.G., Lee, Y.-S., Kim, D.-W., (). Cross-linked composite gel polymer electrolyte using mesoporous methacrylate-functionalized $\quad \mathrm{SiO} 2$ nanoparticles for lithium-ion polymer batteries. Sci. Rep. 2016. 6, 26332.

Shi, H. Hudson L. G., K. J. Liu, "Oxidative stress and apoptosis in metal ion-induced carcinogenesis," Free Radical Biology and Medicine, 2004; vol. 37, no. 5, pp. 582-593.

Sharma V, Singh P, Pandey AK, Dhawan A. Induction of oxidative stress,

DNA damage and apoptosis in mouse liver after sub-acute oral exposure to zinc oxide nanoparticles. Mutat Res 2012; 745: 84-91.

Shobha RI, Andallu B. Radical scavenging and antiperoxidative efficacy of aniseeds (Pimpinella anisum L.): identification of phytoceuticals. Pharmaceutical and biological evaluations. 2015; 2(5):197-203.
Shukla R. K., Sharma, V., Pandey A. K, Singh S., Sultana S., Dhawan A., "ROS-mediated genotoxicity induced by titanium dioxide nanoparticles in human epidermal cells," Toxicology in Vitro, 2011; 25(1) 231-241.

Shvedova, A. A. Pietroiusti, A. Fadeel, B.and V. E. Kagan, "Mechanisms of carbon nanotubeinduced toxicity: focus onoxidative stress," Toxicology and Applied Pharmacology, 2012; vol. 261, no. 2, pp. 121-133.

Soheili S Saeed M, Attaollah S, Masoud G. Histopathological Effects of $\mathrm{ZnO}$ Nanoparticles on Liver and Heart Tissues in Wistar Rats. Advances in Bioresearch. Adv Biores 2013; 4: 83-88.

Teow Y, Asharani PV, Hande MP, Valiyaveettil S. Health impact and safety of engineered nanomaterials. Chem Commun (Camb) 2011; 47: 7025-7038.

Toma C, Pancan I, Chirita $\mathrm{M}$ and Zamfir A: Electrospray ionization tandem mass spectrometric investigation of Melissa officinalis oil. Pharma, 2008; 56(1): 92-98.

Tribowo JA, Arizal MH, Nashrullah M, Aditama AR, Utama DG. Oxidative stress of cadmiuminduced ovarian rat toxicity. Int J Chem Eng App 2014; 5(3): 145.

Valko M, Leibfritz D, Moncol J, Cronin MT, Mazur M, Telser J. Free radicals and antioxidants in normal physiological functions and human disease. Int J Biochem Cell Biol 2006; 39(1): 44-84.

Valko, M. Rhodes, C. J. Moncol, J. Izakovic, M. Mazur, M. "Free radicals, metals and antioxidants in oxidative stress induced 
cancer," Chemico-Biological Interactions, 2006; vol. 160, no. 1, pp. 1-40.

Wang B, Feng W, Wang M. Acute toxicological impact of nano- and submicro-scaled zinc oxide powder on healthy adult mice. J Nanopart Res 2008; 10:263-276.

Wiking L, Larsen T, Sehested J. Transfer of dietary zinc and fat to milk- evaluation of milk fat quality, milk fat precursors, and mastitis indicators. J Dairy Sci, 2008; 91(4):15441551.

Yang W., Lu J., Weng J., et al. China National Diabetes and Metabolic Disorders Study Group.
Prevalence of diabetes among men and women in China. N Engl J Med. 2010; 362: 1090-1101.

Yilmaz O, Ersan Y, Ozsahin AD, Ozturk AI, Ozkan Y. Consequences of the combined $\alpha$-tocopherol, ascorbic acid, and $\alpha$-lipoic acid on the glutathione, cholesterol and fatty acid composition in muscle and liver of diabetic rats. Iran J Basic Med Sci 2013; 16:165-172.

Zhu W, Zhang Y, Huang Y, Lu L. Chapter twelve Chinese herbal medicine for the treatment of drug addiction. Int Rev Neurobiol. 2017; 135: 279-295. 